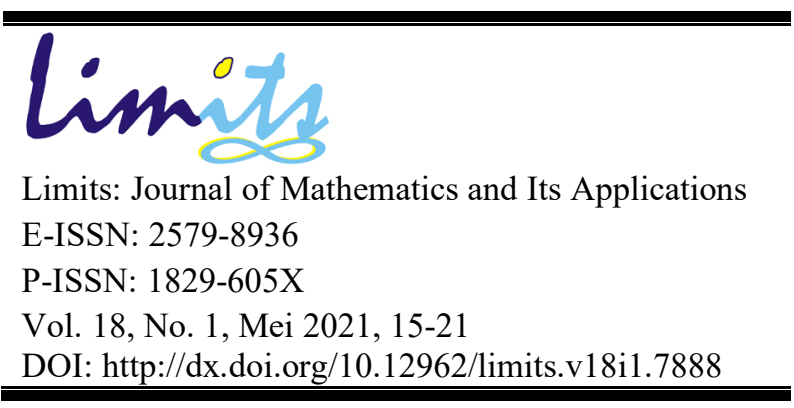

\title{
Pergerakan Aliran MHD Ag-AIR Melewati Bola Pejal
}

\author{
Yolanda Norasia ${ }^{1}$, Basuki Widodo ${ }^{2}$, Dieky Adzkiya ${ }^{2}$ \\ ${ }^{1}$ Jurusan Pendidikan Matematika, UIN Walisongo, Semarang, \\ ${ }^{2}$ Jurusan Matematika, Institut Teknologi Sepuluh Nopember, Surabaya, Indonesia \\ email: yolandanorasia@walisongo.ac.id
}

Diajukan: 21 Oktober 2020, Diperbaiki: 10 Maret 2021, Diterima: 31 Maret 2021

\begin{abstract}
Abstrak
Fluida merupakan zat yang dapat mengalir dan mengalami perubahan secara kontinu akibat adanya tegangan geser. Analisis pengukuran dari ketahanan fluida terhadap tegangan geser menggunakan viskositas. Berdasarkan viskositas, fluida dibagi menjadi dua yaitu fluida newtonian dan fluida nonnewtonian. Fluida non-newtonian terdiri atas fluida viskos, fluida mikropolar dan fluida nano. Salah satu contoh fluida nano adalah Ag-Air. Fluida tersebut tersusun dari fluida dasar air dan partikel nano $\mathrm{Ag}$ yang memiliki daya hantar dan tingkat konduktivitas yang tinggi. Adanya pengaruh medan magnet pada Fluida nano $A g$-Air, maka menjadi fluida tersebut dapat menghantarkan arus listrik (memiliki sifat magnetohidrodinamik/MHD). Merujuk pada hasil riset sebelumnya bahwa parameter magnetik dan konveksi dapat mempengaruhi profil kecepatan dan temperatur pada fluida. Pada penelitian ini dibahas mengenai model matematika dan penyelesaian numeriknya dari permasalahan pergerakan aliran MHD $A g$ Air yang melewati bola pejal dengan pengaruh parameter magnetik dan konveksi. Diperoleh hasil bahwa variasi magnetik yang meningkat mengakibatkan pergerakan $A g$-Air melambat dan temperatur $A g$-Air meningkat. Dengan meningkatkan parameter konveksi diperoleh pergerakan Ag-Air lebih cepat dan temperatur $A g$-Air mengalami penurunan.
\end{abstract}

Kata Kunci: Fluida Nano, Ag-Air, Parameter Magnetik, Parameter Konveksi.

\begin{abstract}
Fluid is a substance that can flow and change continuously due to shear stress. Measurement analysis of fluid resistance to shear stress using viscosity. Based on the viscosity, fluids are divided into two, namely Newtonian fluids and non-Newtonian fluids. Non-Newtonian fluids consist of viscous fluids, micropolar fluids and nano fluids. One example of a nano fluid is Ag-Water. This fluid is composed of water and nanoparticles Ag which has high conductivity and level of conductivity. The influence of magnetic fields on Ag-Water nano fluid, then this fluid can conduct electric current (magneto hydro dynamic/ MHD properties). Referring to the results of previous research that magnetic and convection parameters can affect velocity and temperature profiles in the movement of fluids. This research discusses the mathematical model and its numerical solution of the MHD Ag-Water flow movement problem passing through a solid ball is influenced by magnetic and convection parameters. The results showed that the increasing magnetic variation resulted in the movement of Ag-Water slowing down and the Ag-Air temperature increasing. By increasing the convection parameter, it is obtained that the movement of Ag-Water is faster and the temperature of Ag-Water has decreased.
\end{abstract}

Keywords: Nano fluid, Ag-Water, Magnetic Parameters, Convection Parameter 


\section{Pendahuluan}

Fluida adalah zat yang dapat berubah bentuk secara kontinu apabila terkena tegangan geser [1]. Tegangan geser terjadi akibat adanya laju deformasi pada fluida. Semakin besar laju deformasi maka tegangan geser juga mengalami peningkatan. Analisis pengukuran dari ketahanan fluida terhadap laju deformasi menggunakan viskositas. Berdasarkan viskositas, fluida dibagi menjadi dua yaitu fluida newtonian dan fluida non-newtonian. Fluida newtonian adalah fluida yang tegangan gesernya berbanding lurus dengan gradien kecepatan, seperti air, etanol, dan benzene. Berkebalikan dengan fluida newtonian, fluida non-newtonian bersifat kental karena mengalami pergeseran akibat adanya gaya yang bekerja pada fluida. Fluida non-newtonian berupa fluida viskos, fluida mikropolar, dan fluida nano. Fluida nano merupakan larutan yang mengandung partikel nano dengan ukuran satu sampai 100 nanometer $(\mathrm{nm})$ dalam fluida dasar [2]. Fluida dasar (base fluid) dapat berupa air dan partikel nano berupa logam yakni $\mathrm{Ag}$ (Perak). Partikel nano $\mathrm{Ag}$ memiliki daya hantar dan tingkat kondutivitas yang tinggi [3]. Adanya pengaruh medan magnet pada Fluida nano $\mathrm{Ag}$-Air, maka menjadi fluida tersebut dapat menghantarkan arus listrik. Dengan kata lain, fluida tersebut memiliki sifat MHD (Magnetohidrodinamik).

Penerapan MHD banyak diterapkan dalam perkembangan teknologi dan industri, contohnya pada pengeboran minyak, pemipaan zat-zat kimia pada pabrik dan penggerak pada kapal. Fluida nano dengan sifat MHD mampu mengoptimalkan perpindahan panas dan mengontrol separation flow [4]. Merujuk pada hasil riset sebelumnya, selain medan magnet, profil kecepatan dan temperatur pada fluida juga dapat dipengaruhi oleh konveksi. Terdapat beberapa penelitian mengenai pengaruh konveksi pada aliran fluida seperti pada penelitian [5] tentang model aliran konveksi pada fluida viskoelastik yang melewati sebuah bola dan dikaji pengaruh parameter konveksi yang mempengaruhi karakteristik aliran fluida.

Dalam penelitian ini dikaji dan diteliti mengenai pergerakan aliran fluida nano $\mathrm{Ag}$-Air yang melewati bola pejal dengan pengaruh medan magnet dan konveksi secara teori dengan membuat model matematikanya. Selanjutnya disimulasikan secara numerik menggunakan metode Euler Implicit untuk mengkaji pergerakan fluida terhadap profil kecepatan dan temperatur pada aliran fluida dengan perangkat lunak MATLAB.

\section{Metode Penelitian}

Metode penelitian terdiri atas studi literatur, pembangunan model matematika, penyelesaian model, simulasi, analisis dan pembahasan, dan finalisasi. Pada tahap pembangunan model merujuk 
pada hukum-hukum fisika yang berkaitan dengan permasalahan. Selanjutnya diselesaikan secara numerik menggunakan metode Euler Implicit.

\section{Hasil dan Pembahasan}

Pada penelitian ini, persamaan pembangun yang digunakan adalah persamaan kontinuitas, persamaan momentum linier, dan persamaan energi yang diuraikan dari hukum konservasi massa, hukum II Newton, dan hukum I Termodinamika pada kondisi unsteady state dan incompressible, adalah

$$
\begin{gathered}
\frac{\partial}{\partial \bar{x}}(\bar{r} \bar{u})+\frac{\partial}{\partial \bar{y}}(\bar{r} \bar{v})=0 \\
\rho_{f n}\left(\frac{\partial \bar{u}}{\partial \bar{t}}+\bar{u} \frac{\partial \bar{u}}{\partial \bar{x}}+\bar{v} \frac{\partial \bar{u}}{\partial \bar{y}}\right)=-\nabla p+\mu_{f n} \nabla^{2} \mathbf{V}+\sigma\left(\mathrm{B}_{0}\right)^{2} \bar{u}+\left(\rho_{f n}-\rho_{\infty}\right) g_{\bar{x}} \\
\rho_{f n}\left(\frac{\partial \bar{v}}{\partial \bar{t}}+\bar{u} \frac{\partial \bar{v}}{\partial \bar{x}}+\bar{v} \frac{\partial \bar{v}}{\partial \bar{y}}\right)=-\nabla p+\mu_{f n} \nabla^{2} \mathbf{V}+\sigma\left(\mathrm{B}_{0}\right)^{2} \bar{v}+\left(\rho_{f n}-\rho_{\infty}\right) g_{\bar{y}} \\
\left(\frac{\partial \bar{T}}{\partial \bar{t}}+\bar{u} \frac{\partial \bar{T}}{\partial \bar{x}}+\bar{v} \frac{\partial \bar{T}}{\partial \bar{y}}\right)=\alpha_{f n}\left(\frac{\partial^{2} \bar{T}}{\partial \bar{x}^{2}}+\frac{\partial^{2} \bar{T}}{\partial \bar{y}^{2}}\right)
\end{gathered}
$$

dengan

$\bar{r} \quad$ : jari jari bola pejal

$\bar{u} \quad$ : komponen kecepatan fluida pada sumbu-x

$\bar{v} \quad$ : komponen kecepatan fluida pada sumbu-y

$g_{\bar{x}} \quad$ : percepatan grafitasi sumbu-X

$g_{\bar{y}} \quad$ : percepatan grafitasi sumbu-y

p : tekanan

$\alpha_{f n} \quad$ : difusivitas panas fluida nano

$\rho_{f n} \quad$ : massa jenis fluida nano

$\rho_{\infty} \quad$ : massa jenis fluida dasar air lapisan batas

$\mu_{f n} \quad$ : viskositas fluida nano

$\sigma \quad$ : konduktivitas listrik

$B_{0} \quad$ : besar medan magnet dari bola

Fluida yang digunakan adalah $\mathrm{Ag}$-Air, maka dengan substitusi variabel-variabel yang berhubungan antara partikel $\mathrm{Ag}$ dengan air diberikan sebagai berikut [6]. 
Densitas Fluida Nano

$$
\rho_{f n}=(1-\chi) \rho_{f}+\chi \rho_{s}
$$

Viskositas

$$
\mu_{f n}=\mu_{f} \frac{1}{(1-\chi)^{2.5}}
$$

Kalor spesifik Fluida Nano

$$
\left(\rho C_{p}\right)_{f n}=(1-\chi)\left(\rho C_{p}\right)_{f}+\chi\left(\rho C_{p}\right)_{s}
$$

Konduktivitas termal

$$
k_{f n}=\frac{k_{s}+2 k_{f}-2 \chi\left(k_{s}-k_{f}\right)}{k_{s}+2 k_{f}+\chi\left(k_{s}-k_{f}\right)} k_{f}
$$

maka diperoleh

$$
\begin{gathered}
\frac{\partial u}{\partial t}+u \frac{\partial u}{\partial x}+v \frac{\partial u}{\partial y}=-\frac{\partial p}{\partial x}+\left(\frac{1}{(1-\chi)^{2.5}} \frac{1}{(1-\chi)+\chi\left(\frac{\rho_{s}}{\rho_{f}}\right)}\right) \frac{\partial^{2} u}{\partial y^{2}}+M u+\lambda T \sin x \\
\left(\frac{\partial T}{\partial t}+u \frac{\partial T}{\partial x}+v \frac{\partial T}{\partial y}\right)=\frac{1}{P r} \frac{k_{s}+2 k_{f}-2 \chi\left(k_{s}-k_{f}\right)}{k_{s}+2 k_{f}+\chi\left(k_{s}-k_{f}\right)} \frac{1}{(1-\chi)+\chi\left(\frac{\left(\rho C_{p}\right)_{s}}{\left(\rho C_{p}\right)_{f}}\right)} \frac{\partial^{2} T}{\partial y^{2}}
\end{gathered}
$$

untuk menghubungkan dua fungsi kecepatan pada $\mathrm{u}$ dan $\mathrm{v}$ pada bidang $-\mathrm{x}$ dan $-\mathrm{y}$, digunakan fungsi alir sebagai berikut [7]

$$
u=\frac{1}{r} \frac{\partial \psi}{\partial y} \operatorname{dan} v=-\frac{1}{r} \frac{\partial \psi}{\partial x}
$$

dengan melakukan substitusi Persamaan (7) ke Persamaan (5) dan (6), sehingga

$$
\begin{aligned}
& \left.\left[\frac{1}{(1-\chi)^{2.5}\left[(1-\chi)+\left(\frac{\rho_{s}}{\rho_{f}}\right)\right]}\right] \frac{\partial^{3} f}{\partial \eta^{3}}+\frac{\eta^{2} f}{2 \partial \eta^{2}}+\frac{3}{2} t \cos x\left[1-\left(\frac{\partial f}{\partial \eta}\right)^{2}+2 f \frac{\partial^{2} f}{\partial \eta^{2}}\right)\right] \\
& =t \frac{\partial^{2} f}{\partial \eta \partial t}+\frac{3}{2} t \sin x\left(\frac{\partial f}{\partial \eta} \frac{\partial^{2} f}{\partial x \partial \eta}-\frac{\partial f}{\partial x} \frac{\partial^{2} f}{\partial \eta^{2}}\right)+M t\left(1-\frac{\partial f}{\partial \eta}\right)-\frac{2}{3} \lambda s t \\
& \left(\frac{k_{s}+2 k_{f}-2 \chi\left(k_{s}-k_{f}\right)}{k_{s}+2 k_{f}+\chi\left(k_{s}-k_{f}\right)} \frac{1}{(1-\chi)+\chi\left(\frac{\left(\rho C_{p}\right)_{s}}{\left(\rho C_{p}\right)_{f}}\right)}\right) \frac{\partial^{2} s}{\partial \eta^{2}}+\operatorname{Pr} \frac{\eta}{2} \frac{\partial s}{\partial \eta}+3 \cos x \operatorname{Pr} t \frac{\partial s}{\partial \eta}=\operatorname{Pr} t \frac{\partial s}{\partial \eta}+\operatorname{Pr} t \frac{3}{2} \sin x\left(\frac{\partial f}{\partial \eta} \frac{\partial s}{\partial x}-\right. \\
& \left.\frac{\partial f}{\partial x} \frac{\partial s}{\partial \eta}\right)
\end{aligned}
$$


Pada simulasi dari model yang telah dikerjakan, dilakukan variasi parameter non dimensional yaitu parameter magnetik dan konveksi. Partikel yang digunakan adalah partikel nano Ag yang memiliki nilai kapasitas panas $\left(c_{p}\right)$, densitas $(\rho)$ dan konditivitas termal $(k)$ seperti pada Tabel 1.

Tabel 1. Sifat Thermo-physical Ag-Air

\begin{tabular}{ccc}
\hline Sifat Thermo-physical & Air & Partikel $\boldsymbol{A g}$ \\
\hline$\rho\left(k g / \mathrm{m}^{3}\right)$ & 997.1 & 10500 \\
$c_{p}\left(\frac{\mathrm{J}}{\mathrm{kg} \mathrm{K}}\right)$ & 4179 & 236 \\
$k\left(\frac{\mathrm{W}}{\mathrm{mK}}\right)$ & 0.613 & 427 \\
\hline
\end{tabular}

Simulasi ini bertujuan untuk mengetahui pengaruh variasi parameter magnetik pada pergerakan aliran MHD Ag-Air terhadap profil kecepatan dan profil temperatur, sehingga diberikan nilai inputan variasi magnetik yaitu $0,1,3,5$ dan 7 .

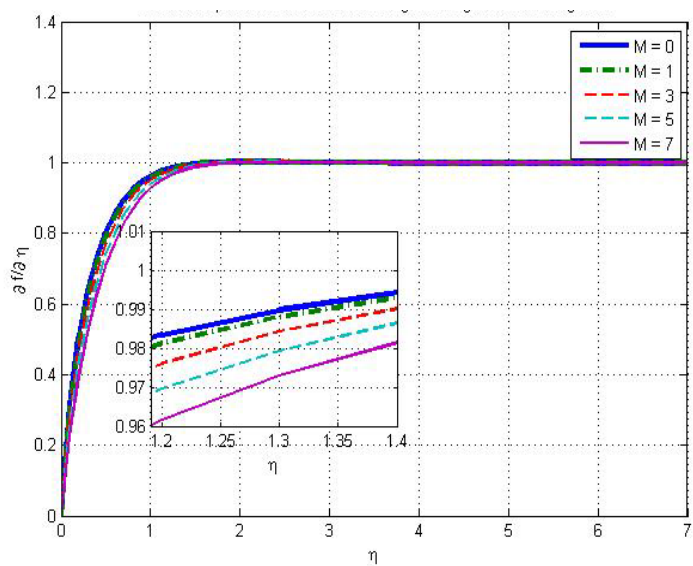

Gambar 1. Kurva Kecepatan Variasi Magnetik

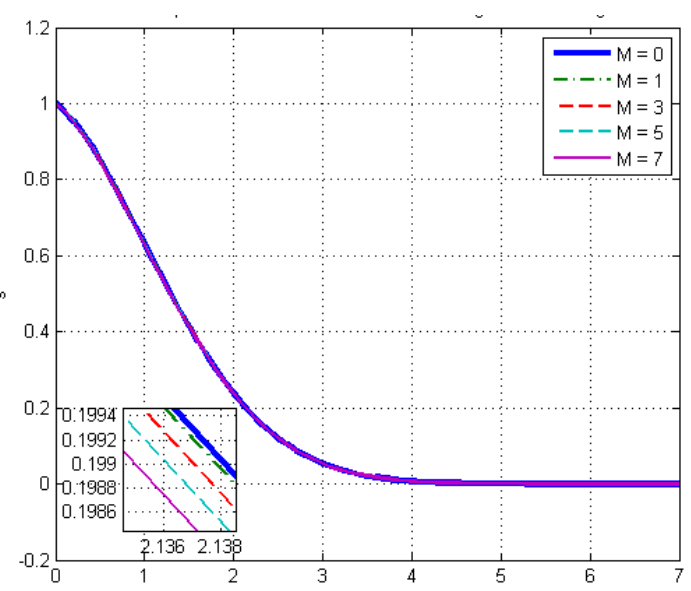

Gambar 2. Kurva Temperatur Variasi

Magnetik

Pada Gambar 1 menunjukkan kurva kecepatan mengalami peningkatan mulai dari $f^{\prime}=0$ sampai $f^{\prime} \approx 1$. Sedangkan Gambar 2 kurva temperatur menunjukkan terjadi penurunan pada profil temperatur fluida nano mulai dari $s=1$ sampai $s \approx 0$. Pada saat $0<\eta<5$, parameter magnetik yang lebih besar bergerak lebih lambat untuk mencapai kecepatan maksimum. Hal tersebut merupakan akibat pengaruh gaya Lorentz dari bola pejal bermagnet. Gaya Lorentz berbanding lurus dengan besarnya medan magnet, sehingga semakin meningkatnya gaya magnet pada bola, maka pergerakan fluida Ag-Air mengalami perlambatan. Medan magnet dari bola pejal menimbulkan energi internal $\mathrm{Ag}$-Air semakin meningkat. Hal ini mengakibatkan temperatur fluida mengalami penurunan seiring penambahan parameter magnetik. 


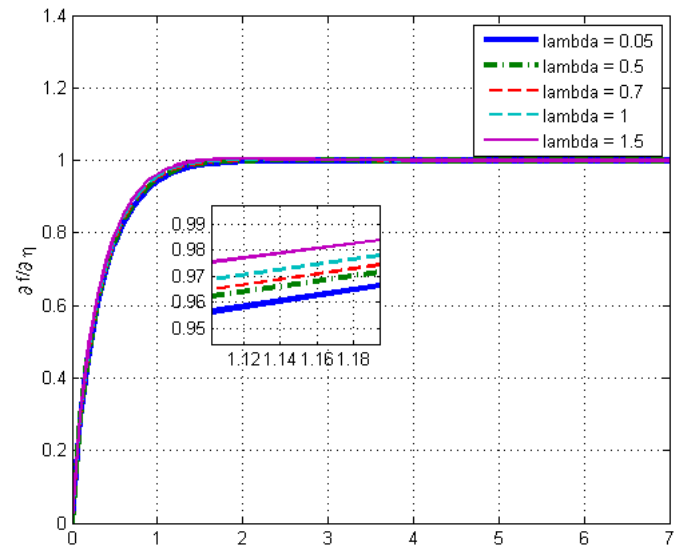

Gambar 3. Kurva Kẻcepatan Variasi Konveksi

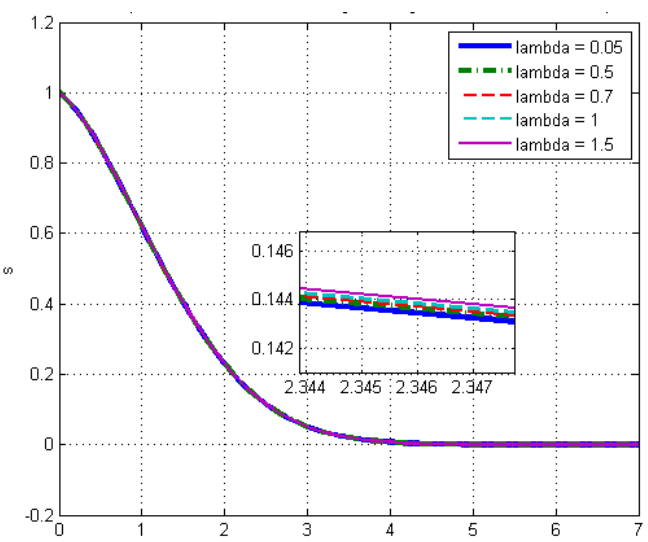

Gambar 4. Kurva Temperatur Variasi Konveksi

Pada Gambar 3 menunjukkan kurva kecepatan mengalami peningkatan mulai dari nol sampai mendekati satu. Kecepatan aliran fluida dengan variasi parameter konveksi bergerak dari nol dan konvergen ke satu. Kecepatan maksimum adalah satu, mengikuti kecepatan aliran bebas $U_{\infty}$. Koefisien konveksi berbanding lurus dengan suhu fluida, akibatnya semakin besar variasi pada parameter konveksi, maka aliran fluida bergerak lebih cepat mencapai kecepatan maksimum. Sebaliknya, Pada Gambar 4 menunjukkan penurunan pada profil temperatur $A g$-Air mulai dari $s=$ 1 sampai dengan $s \approx 0$. Pengamatan terhadap variasi konveksi menunjukkan bahwa profil temperatur mengalami penurunan. Hal ini terjadi karena koefisien konveksi berbanding lurus dengan suhu fluida.

\section{Simpulan}

Penelitian ini mempelajari pergerakan aliran fluida nano $\mathrm{Ag}$-Air yang melewati bola pejal dengan pengaruh medan magnet dan konveksi. Model matematika aliran fluida nano Ag-Air yang telah diperoleh diselesaikan dengan menggunakan metode Euler Implicit. Variasi magnetik yang meningkat mengakibatkan pergerakan $A g$-Air melambat dan temperatur $A g$-Air meningkat karena adanya pengaruh gaya Lorentz. Variasi konveksi yang meningkat mengakibatkan pergerakan $\mathrm{Ag}$ Air lebih cepat dan temperatur $A g$-Air menurun. Hal ini terjadi karena koefisien konveksi berbanding lurus dengan suhu fluida.

\section{Daftar Pustaka}

[1] Widodo, B., Pemodelan Matematika, ITSpress, Surabaya, 2012

[2] Ramadhan, A. I., Analisis Perpindahan Panas Fluida Pendingin Nano fluida Di Teras Reaktor PWR (PressurizedWater Reactor) Dengan Computational Fluid Dynamics, Tesis Program Magister, Universitas Pancasila, Jakarta, 2012. 
[3] Ekpunobi, U.E. Okwukogu, O.K. Anozie, A.I. Ogbuagu, A. S. Ajiwe, V.I. dan C.I. Nwezw., Deposition and Characterization of Silver Oxide from Silver Solution Recovered from Industrian Waste, American Chemical Science Journal. Volume 3(3): 307-312, 2013.

[4] Widodo, B., Arif, D.K., Aryany, D., Asiyah, N., Widjajati, F.A., \& Kamiran., The Effect of Magnetohydrodynamic Nano Fluid Flow Through Porous Cylinder, AIP ADVANCES, 6, 020069, 2017.

[5] Ghani, M., Widodo, B. dan Imron, C. Model Aliran Konveksi Campuran yang Melewati Permukaan Sebuah Bola, Seminar Nasional Pendidikan Matematika Ahmad Dahlan, Yogyakarta, 2014.

[6] Rabeti, M.,Mixed Convection Heat Transfer of Nanofluids about a Horizontal Circular Cylinder in Porous Media, SOP Transaction on Nano Technology, volume 1, number 1, 2014.

[7] Widodo, B., Anggriani, I., Imron, C., The Characterization Of Boundary Layer Flow in The Magnetohydrodynamic Micropolar Fluid Past A Solid Sphere, International Journal of Advances in Science Engineering and Technology, ISSN:2321-9009, 2016. 